\title{
Importance of Cinnamomum Tamala in the Treatment of Various Diseases
}

\author{
Shashank Tiwari ${ }^{1}, *$, Shreya Talreja ${ }^{2}$
}

Shashank Tiwari ${ }^{1, *}$, Shreya

Talreja $^{2}$

'Director (Academic \& Research), Lucknow Model College of Pharmacy, Lucknow, INDIA. Shreya Talreja, Lecturer, Lucknow Model College of Pharmacy, Lucknow, INDIA. 'Lecturer, JP College of Pharmacy, Lucknow, INDIA.

\section{Correspondence \\ Shashank Tiwari}

Director (Academic \& Research), Lucknow Model College of Pharmacy, Lucknow INDIA.

E-mail: shashank6889@gmail.com

History

- Submission Date: 03-08-2020;

- Review completed: 11-09-2020;

- Accepted Date: 22-09-2020

DOI : 10.5530/pj.2020.12.241

Article Available online http://www.phcogj.com/v12/i6s

\section{Copyright}

(C) 2020 Phcogj.Com. This is an openaccess article distributed under the terms of the Creative Commons Attribution 4.0 International license.

\begin{abstract}
Cinnamomum tamala is a multipurpose evergreen plant it is a native of India. The plant is commonly known as Indian cassia, Tejpatta, Indian bay leaf etc. All parts of plant possess many major bioactive constituent due to the presence of major phytoconstituent it is useful for the treatment of various diseases or disorders such as Cancer, cardiac diseases, diabetes, Anxiety, depression, ulcer, GI diseases and possess many pharmacological activity includes anti-oxidant, anti-hypercholesterolemia, anti-diarrhoeal, anti-inflammatory, anti-fungal, antibacterial etc. In Ancient time the plant also used as for its medicinal value and it contains a aromatic property due to the presence of these property it is used in perfumery industry and used as mouth refreshing, useful for removal of bad odour from body, mouth and also used in pharmaceutical industries. The leaves of the plant possess flavouring agent property it is used as a flavouring agent in food, curry, fast food, pickles and used as a spice. The main aim of this review/study was to promote and upgrade the knowledge of the use of this multipurpose evergreen plant.
\end{abstract}

Key words: Cinnamomum tamala, Pharmacological activity, Diseases, Uses.

\section{INTRODUCTION}

Cinnamomum tamala (C. tamala) is a multipurpose valued, Perennial plant. It is commonly known as Tezpat/ Tezapatta or Indian Cassia and Indian bay leaf. Its belongs to Lauraceae Family. ${ }^{1}$ It is mainly found in moist slopes of Himalayan regions at height up to $900 \mathrm{~m}$ to $2500 \mathrm{~m}$. Regions like uttrakhand, Manipur, nainital, Himachal Pradesh, Assam, Arunachal Pradesh and some hills area includes mikir hill, garo hill, khasi hill, nilgiri hill jaintia hill and also found some regions of india, Nepal, Bhutan, China. ${ }^{2-4}$ The plant contains a up to 7-12m height, rugged bark which is dark brown to reddish brown in colour. And the leaf of the plant is thickened, ovate shaped and glossy in appearance. It is commonly used for its aromatic property in food, used in some perfumery industry for fragrance, used in pharmaceutical industries because it possess many medicinal property $^{5,6}$ and leaves extract of plant is used as clarifier in dyeing method. In anient time the plant parts are also used in ayurveda system of medicine for preparation of Ayurvedic formulations includes Sudarshan choorna, chandraprabhavati. ${ }^{7}$ The plant possess a various pharmacological/ medicinal property useful for cure and treat various diseases due to the presence of many major bioactive constituents such as:-

Cinnamaldehyde, trans-cinnamaldehyde, 3,4,5,7tetrahyroxyflavone, 3,3,4,5,7- pentahydroxyflavone (non-glycoside compounds), kaempferol-3-Oglycopyranoside (Astragalin), quercetin-3-Orutinoside, quercetin-3-O-sophoroside (flavonoid glycoside), kaempferol-3,7di-O-rhamnopyraoside, a-pinene, myrcene, camphene, p-cymene, limonene, eugenol (4-hydroxy-3-methoxyallylbenzene), methyl eugenol, methyl ether eugenol and eugenol acetate. ${ }^{8-11}$ In the evaluation of leaf oil of plant the study found that plant leaf oil possess a major bioactive compound includes Furanogermenone, $\beta$ - caryophyllene, germacerene d, curcumenol, curzerenone, furanodiene, furanodienone, and contains a rich amount of sesquiterpenoids compounds, and mainly contains some other phytochemical compounds cinnamaldehyde, eugenol,a- linalool, carophyllene oxide, geraniol, Benzaldehyde, 1,8-cineole, Salicylaldehyde, $\gamma$-terpinene, acetophenone, cis-sabinene hydrate, trans-sabinene hydrate, 3-phenyl propanala, Pinocarvone, borneol, 2-methylbenzofuran, tepinen4-ol, p-cymen-8-ol, a-terpineol, bornyl acetate, cinnamyl alcohol, hydrocinnamyl acetate, cinnamyl acetate, cinnamic acid, coumarin, cinnamyl acetate, a-humulene, nerolidol, spathulenol, Monoterpenoid Hydrocarbons, Oxygenated Monoterpenes, Sesquiterpens Hydrocarbons, Oxygenated Sesquiterpens, Phenylpropanoids and also includes in small quantity of $\alpha$ - humulene, $\alpha$ - muurolene. ${ }^{1,8,3,9}$

Numerous researchers study shown that the tejpatta possess a various pharmacological activity such as anti-hyperlipidemic activity, anti-diabetic activity, gastro protective activity, anti-helminthic/ antiprotozoal activity, anti-inflammatory property, antiemetic activity, anti-diarrhoeal, antifungal activity, it shown potent antibacterial property against various micro-organism such as Escherichia coli (E.Coli), Bacillus subtilis, Saccharomyces cerevisiae, anti-oxidant property, free radical scavenging activity also exhibit CNS protective activity like anticonvulsant, hypothermic activity. The extract of plant reduces the oxidative damage and useful 
for the protective against renal toxicity induced by gentamicin etc. and useful for treat various diseases includes anal and rectal disease, protective against flatulence, cancer, coryza (inflammation in mucous membrane), anorexia, liver and spleen diseases, prevent bleeding (used as a coagulanting agent), cardio vascular diseases and used for induce blood circulation. leaves oil is useful for dermatophytic infection. ${ }^{10-12}$ Tejpatta leaves is commonly used in foods, beverages, pickles, meats, fast foods, chewing gums as a flavouring agents, ${ }^{6}$ it is also exhibit a mouth freshening property. It is a natural food preservative agent used in some juices like pineapple juice. In another hand the plant possess many other beneficial effect against nematode worms (used as nematicidal), useful to kill the insects in crops (insecticidal), exhibits mosquito larvicidal activity (kill mosquito/larvae), useful for pest control in field, used as anti-termitic agent (Table 1). ${ }^{5,13}$

\section{MORPHOLOGY CHARACTERISTICS OF C. TAMA- LA PARTS $5,6,8,3$}

All parts of plant possess a various different property which is useful for treat and cure many disease and contains a many major bioactive compounds and various pharmacological activity and also used as a commonly in spices, flavouring agent it is aromatic in nature (possess pleasant odour) and clove like taste. Some morphological properties of plant parts are discussed in below (Figure 1 and Table 2).

Used Plant Parts: - Bark, Leaves, Fruit, Flowers, Seeds etc.

Bark:- The plant contains a up to $7 \mathrm{~m}$ height, branches up to $95 \mathrm{~cm}$ width, rugged bark which is greyish red to dark brown in colour. Bark of the plant produces a mucilage/gum.

Leaves:- Leaves of the plant is thickened, pointed/acuminate ovate shape. It is $12-20 \mathrm{~cm}$ long, $5-8 \mathrm{~cm}$ wide (centre), Progeny/Young leaves are reddish pink in colour and after some time leaves colour is change (dark green), glossy appearance. leaves of the plant consist a 3 nerves like line from the base to top. The taste of leaves is clove like and odour is pepper like.

Flower:- Tejpatta contains a small epicene flower in same plant, white in colour, long up to $7.5 \mathrm{~mm}$. Twigs of the flower are long same as calyx. It is cross fertilized/ Pollinated by honey bees.

Table 1: Scientific/Botanical Classification of C.tamala. ${ }^{1,8,3}$

\begin{tabular}{cc}
\hline Category & Botanical description \\
\hline Kingdom & Plantae \\
Subkingdom & Tracheobionta (vascular plant) \\
Division & Magnoliophyta (flowering plant) \\
Class & Magnoliopsida (Dicotyledons) \\
Subclass & Magnoliidae (group of flowering plant) \\
Order & Laurales \\
Genus & Cinnamomum Schaeff \\
Family & Lauraceae \\
Species & Cinnamomum Tamala (Buch-Ham) \\
Synonym & Cinnamomum albiflorum Nees, Cinnamomum cassia D.Don nom. illeg. \\
\hline
\end{tabular}

Table 2: Various name of C.tamala in Different languages. ${ }^{1,3}$

\begin{tabular}{cc}
\hline Languages & Names \\
\hline Sanskrit & Tamalpatra \\
Hindi & Tejpatta \\
English & Indian Bay Leaf, Indian cassia \\
Marathi & Tamalpatra \\
Tamil & Talishappattiri/ Katu-kurrnap \\
Assam & Tejpat \\
Malayalam & Tamalapatram/ Karuntoli \\
Telugu & Talisapatri \\
Canada & Patraka \\
Bengali & Tejpat \\
\hline
\end{tabular}
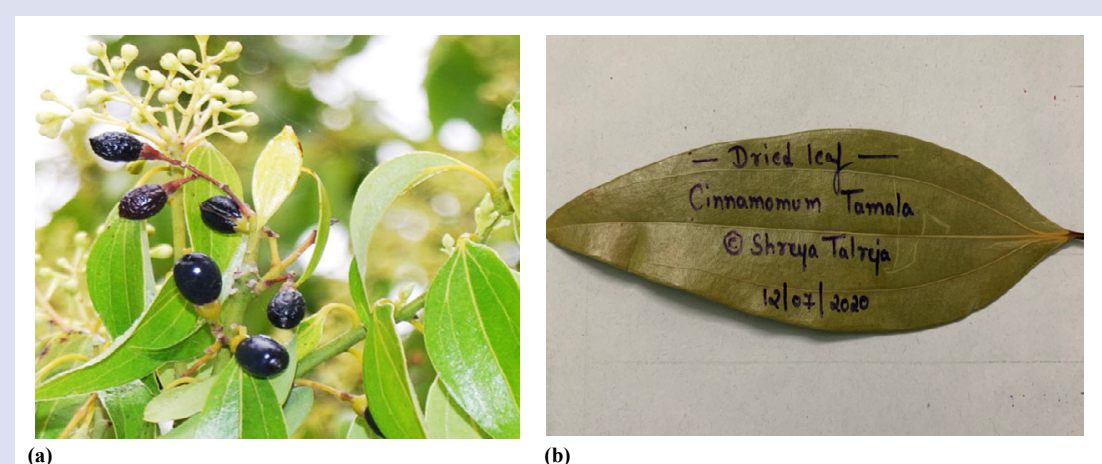

Figure 1: (a):- Image of c.tamala leaves, flower, fruits (Image source- nursery pioneer), ${ }^{26}$ (b): Image of dried leaves of cinnamomum tamala. 
Fruit:- the plant ripe fruit is dark purple colour, ovate drupe (fruit with thin skin and they contain a seed), the plant contains a drupe up to $13 \mathrm{~mm}$ long and the fruit required a seed for 1 year attaining full growth. The fruit contain a single seed.

Flowering \& Fruiting Time:- The flowering period of the plant is March last week to mid-April and fruiting period of plant is April May.

\section{TRADITIONAL USE OF C.TAMALA ${ }^{5,6,14}$}

The plant is used in many years ago in Indian system, ayurvedic system and also traditionally system for its medicinal property, aromatic property and used as a flavouring agent in food detail discussed in below:-

- In traditionally tejpatta is used in food, beverages, fast food, pickle used as a flavouring agent or as a spices and also useful for its aromatic property.

- The presence of flavouring agent, mouth refreshning property the plant is also used in chewing gums and also beneficial for breath problems.

- Tejpatta powder is used for some dental problems like reducing tooth pain.

- Traditionally the plant is useful for the treatment of many diseases and disorders includes colon cancer, Diabetes, cardiac disease, CNS disorders, bleeding disorder (useful for increase blood circulation in uterus) and it is also useful in appetite problem, mouth problems like dryness of mouth, unpleasant/poor breath problem, rheumatism, etc.

- Tejpatta leaves and bark also exhibits astringent, antiemetic, antidiarrhoeal, anti-inflammatory includes wound healing property, carminative property (relieving flatulence).

\section{TAMALA IS USEFUL FOR TREAT VARIOUS DIS- EASES AND DISORDERS}

\section{CNS Disorders (Depression, anxiety)}

Numerous researchers reports shown that the extract of plant possess anti-depressant effect same as imipramine (antidepressant drug) at proper dose administration $(400 \mathrm{mg} / \mathrm{kg}$ ) and in another hand the studied found that plant possess beneficial effect against anxiety disorder (used as a anti-anxiety/anxiolytic agent) and also useful for the treatment or management of psychological disorders. ${ }^{2}$

\section{Useful for the prevention of Gastrointestinal (Gl) diseases}

Leaves Extract of $c$. tamala possess GI protective activity. In the evaluation of study, the orally administration of leaves extract of plant in rats at proper dose level $50 \mathrm{mg} / \mathrm{kg}, 100 \mathrm{mg} / \mathrm{kg}, 100 \mathrm{mg} / \mathrm{kg}$ (Body weight) for 5 day daily twice time. Result found that the extract of plant is effective against cold restraint stress, ethanol, pylorus ligation (increase acid secretion in stomach) which induced gastric ulcer. In other words, say that the leaves extract of plant is useful for the prevention of gastric ulcer. ${ }^{3}$

\section{Useful for the prevention of Renal/nephrotic diseases}

According to Authors c.tamala leaves extract possess renal protective effect against renal toxicity/nephro toxicity induced by gentamicin in rabbit. In Evaluation of study through various histopathological examination/test were measured such as serum creatinine, creatinine clearance, uric acid, volume of urine, blood urea nitrogen, body weight and excretion of urinary protein.
In study ' $A$ ' group rabbits treated with gentamicin. result showed that kidney damage through increase level of blood urea nitrogen, serum creatinine, creatinine clearance, uric acid, increase level of urinary protein and also increases body weight. But In another hand 'B' group rabbits are treated with gentamicin and tejpatta they shown beneficial effect against kidney and shown no any harmful effect against renal function at administration of proper dose level $200 \mathrm{mg} / \mathrm{kg}$ per day. Hence, the study proves that the plant leaves extract is useful and possess significant effect against nephrotoxicity induced by gentamicin. ${ }^{3}$

\section{C. tamala is useful for the treatment of cancer}

The tejpatta plant leaves extract contains a various major bioactive constituents such as bornyl acetate which is useful against cancer (ovarian cancer). Study found that these major bioactive constituent possess cytotoxic effect against cancer cell and decreases the prostate growth and inhibit/reduces the growth of no. of abnormal cell (hyperplastic) and also possess anti-inflammatory activity. ${ }^{2}$

\section{Useful for the treatment of diabetes}

Numerous researchers studied shown that the plant extract contains many phytochemical constituents (procyanidins) which is effective against diabetes/ hyperglycaemia by increasing insulin level through treating pancreatic $\beta$-cells.

Ethanolic extract of the leaves of this plant also shown hypoglycaemic activity through increasing insulin level and also enhance the oral glucose tolerance by inducing the insulin level. Hence, the study proves that the plant possess anti-hyperglycaemic activity by reducing glucose level and induce insulin secretion in pancreatic $\beta$-cells. It possess potent effect against diabetes. ${ }^{2}$

In another study found that the diabetic patient recover delay wound/ cuts or any inflammation due to the presence of high glucose level in blood. The plant extract also contains many phenolic compounds; flavonoids may be due to the presence of thise compounds they possess wound healing activity. ${ }^{15}$

\section{Ulcer Preventive}

The leaves extract (hydro alcoholic) of C.tamala shown protective effect against ulcer. They protect the gastric mucous membrane from secretion of harmful chemicals, stress/pressure, and any cause of ulcer. These extract is useful for block the hydrogen, potassium, ATPase activity and they inhibit/reduce gastric acid secretion. Hence, this shown that the extract of plant is useful for the treatment of ulcer. ${ }^{16}$

\section{Other Diseases}

- Malarial disease the leaves extract (hydro-alcoholic) of $c$. tamala possess inhibitory/protective effect against malaria pathogen (plasmodium falciparum) and also useful for the treatment of malaria. ${ }^{17}$

- Food borne diseases the $c$. tamala leaves oil possess a antifungal activity against many fungi such as Aspergillus niger, A. fumigatus, Candida albicans, Rhizopus stolonifer and Penicillium spp which cause food spoilage and induce the risk of food borne diseases/food poisoning. In this study researchers found that c.tamala plant useful for inhibit the the growth of fungi which cause food spoilage and prevent food borne disease. ${ }^{2}$

\section{Important Pharmacological activity}

\section{C. tamala possess wound Healing Activity}

According to researchers study reports that tejpatta leaves ethanolic extract are possess wound healing property and Earlier study shown the high glucose level cause the delay recovery of wounds and any incision. 
These evaluation of study found in diabetic rat through administration of ethanol extract of leaves tejpatta they promote wound healing activity by reducing glucose level in blood, increase contraction of wound/cuts and also possess increased tensile strength. The plant possess this action due to the presence of many bioactive constituents includes phenolic compounds, tannins etc. ${ }^{6,18}$

\section{Useful for anti-inflammatory Activity}

The leaves powder of tejpatta extracted with distilled water through hot maceration method. These aqueous extract useful for anti-inflammatory activity. The administration of dose $(100 \mathrm{mg} / \mathrm{kg}, 200 \mathrm{mg} / \mathrm{kg}$, and $400 \mathrm{mg} /$ $\mathrm{kg}$ ) in rats and induced paw oedema in rat through carrageenan and acetic acid is used in rat for vascular permeability. The plant extract Anti- inflammatory activity is evaluated through membrane stabilizing property. The aqueous extract inhibit or reduce the oedema in rat induced by carrageenan and also decrease/inhibit vascular permeability induced by acetic acid and the study also found that the In vitro administration of plant extract possess membrane stabilizing activity in conc. Dose dependent manner up to $(1 \mathrm{mg} / \mathrm{ml}) .^{19,10}$

\section{C. tamala exhibits anti hyperlipidemic activity}

Researchers study found that the Aqueous, ethanol extract of leaves of this plant is possess hypo cholestrolemic effect. The ethanol and aqueous leaves extract of plant is administered orally in rats (dose $400 \mathrm{mg} / \mathrm{kg}$ per day) for 10 days. Continuously administration of leaves extract dose results found that prevent or reduce the increased level of serum in total cholesterol, LDL (LOW DENSITY LIPOPROTEIN)/ Bad cholesterol, VLDL(VERY LOW DENSITY LIPOPROTEIN), and increase/improve the level of Good cholesterol/HDL (HIGH DENSITY LIPOPROTEIN). ${ }^{19}$

\section{Plant possess skin whitening property (anti tyrosinase activity)}

The plant exhibit many major bioactive constituents which possess skin whitening property. Compounds are: - cis-2-methoxycinnamic acid, cinnamaldehyde.

These compounds inhibits the activity of tyrosinase enzyme (enzyme is responsible for the production of melanin and other pigments). ${ }^{2}$

\section{C. tamala possess antifungal activity}

Numerous researchers study reports that used in agar diffusion evaluation for these study. leaves oil of this plant are possess potent anti fungal activity against many fungi such as Aspergillus niger, $A$. fumigatus, Candida albicans, Rhizopus stolonifer and Penicillium spp. And leaves oil also useful for the food spoilage.

\section{C. tamala possess antibacterial activity}

The bark extract of the tejpatta is a good source for antibacterial effect and the evaluation is done through using agar diffusion method. And these study show that the plant bark extract is possess anti-bacterial activity. ${ }^{16}$

\section{Ethanobotanical uses ${ }^{1,19}$}

- Bark and dried leaves powder are used for reducing fever, anaemia (lack of blood), unpleasant body odour, bad mouth odour and the plant seed powder are combined with honey prescribed for children in purpose of diarrhoea, cough problem.

- The plant possess aromatic property due to the presence of its property it is useful in perfumery industry and also useful in preparation of soaps, detergents, cosmetics, toothpaste etc and also useful in food industry as a spice.
- C.tamala plant parts are useful for preparation of some ayurvedic formulation like Sudarshan churna, Chandraprabhavati etc.

- Leaves extract of plant used as a clarifier in dyeing method with emblic myrobalans. C.tamala plant is also used as a food, fodder, medicine etc. Numerous study shown that the plant leaves is also use for its green dyeing property.

\section{REFERENCES}

1. Majumder Pulak et al, An ethano-phytochemical and pharmacological review on novel indian medicinal plants used in herbal formulations, International Journal of Pharmacy and Pharmaceutical Sciences, 2013, Vol. 5(4): 74-83.

2. Upadhyay K Ravi, Therapeutic and Pharmaceutical Potential of Cinnamomum Tamala, Research Reviews in Pharmacy and Pharmaceutical Sciences, 2017, 6(3): 18-26.

3. Tiwari, Shashank, and Navneet Batra. "Oral drug delivery system: a review." Am. J. Life. Sci. Res 2.1 (2014): 27-35.

4. Pravin Borhade et al, Recent Pharmacological Review on Cinnamomum tamala,

5. Research Journal of Pharmaceutical, Biological and Chemical Sciences, 2013, Vol. 4(4): 916-921.

6. Jain Anuj et al, Antimicrobial activity of Cinnamomum tamala (Tejpat) against some bacterial and fungal pathogens, Journal of Pharmacy Research, 2011 4(11): 3975-3977

7. Rani Akanksha et al, A review on aroma profile of cinnamomum species in north and north east India, World Journal of Pharmaceutical Research, 2017, Vol. 6(11): 200-221, DOI: 10.20959/wjpr201711-9501.

8. Soni Rupesh et al, Effect of ethanolic extract of cinnamomum tamala leaves on wound healing in stz induced diabetes in rats, Asian J Pharm Clin Res, 2013, Vol 6 (4): 39-42.

9. Sharma Gunjan et al, Cinnamomum tamala: A valuable tree from Himalayas, Int. J. Med. Arom. Plants, 2011, Vol. 1(1): 1-4.

10. Mal D et al, Chemical Constituent of Cinnamom umtamala: An Important Tree Spices, Int.J.Curr.Microbiol.App.Sci, 2018, 7(4): 648-651.

11. Tiwari Shashank et al. An overview on coronil drug, : Journal of global trends in pharmaceutical sciences.(2020), $11(3)$, pp: 8242-8247.

12. Satyal Prabodh et al, Bioactivities and Compositional Analyses of Cinnamomum Essential Oils from Nepal: C. camphora, C. tamala, and C. glaucescens, Natural Product Communications, 2013, Vol. 8 (12):1777-1784.

13. Manoj N Gambhire et al, Anti-inflammatory activity of aqueous extract of Cinnamomum tamala leaves by in vivo and in vitro methods, Journal of Pharmacy Research 2009, 2(9): 1521-1524.

14. Ullah Naveed et al, Protective Effect of Cinnamomum tamala Extract on Gentamicin-Induced Nephrotic Damage in Rabbits, Tropical Journal of Pharmaceutical Research, 2013, 12 (2): 215-219.

15. Tiwari, S., Talreja, S. Do you think disease and disorder are same?-here is the comparative review to brash up your knowledge. J. Pharm. Sci. \& Res. Vol. 12(4), 2020, 462-468.

16. Hassan Waseem et al, Antimicrobial Activity of Cinnamomum tamala Leaves, Journal of Nutritional Disorders \& Therapy, 2016, 6(2): 2-5, DOI: 10.4172/21610509.1000190

17. Singh Jyoti et al, Phytochemical screening and antimicrobial studies of cinnamomum tamala, J. Global Trends Pharm Sci, 2019, 10(3): 6606 - 6612.

18. Tiwari, Shashank, Sachin Saxena, and Rohit Kumar. "Process Scale Up of Ibrufen Tablet." Journal of Pharmaceutical Sciences and Research 3.10 (2011): 1525.

19. Rao V Pasupuleti et al, Cinnamon: A Multifaceted Medicinal Plant, Hindawi Publishing Corporation, 2014, DOI- http://dx.doi.org/10.1155/2014/642942

20. Patley Chakresh et al, Investigating the Wound Healing Effect of Cinnamomum Tamala Leaves in Diabetic Rats, International Journal of Pharmacy and Drug Research, 2017, Vol. 3 (1):1-5

21. Tiwari Shashank, Unit Dosage form Tablet: An Overview, International Research Journal of Humanities, Engineering and Pharmaceutical Sciences, 2015, Vol. 1(9): 8-36.

22. Shah Megha et al, Ethanopharmacological properties of cinnamomum tamalaA review, International Journal of Pharmaceutical Sciences Review and Research, 2010, Vol. 5(3): 141-144.

23. Gupta Karan et al, Antimalarial Activity of Cinnamomum Tamala, International Journal of Medical Science in Clinical Research and Review, 2018, Vol. 1(1): 1-10.

24. Tiwari, Shashank. "A Comparative Review on Avanafil vs Tadalafil vs Sildenafil Tablet." Journal of Pharmaceutical Sciences and Research 12.5 (2020): 598-601.

25. Mohan Manindra, Antimicrobial activity and composition of the volatiles of Cinnamomum tamala Nees. and Murraya koenigii (L.) Spreng. from Uttarakhand (India), Asian Pacific Journal of Tropical Disease, 2012, S324-S327 
26. Mehta Seema, Pharmacological Activities of Cinnamomum tamala Nees \& Eberm. and Medical Implication: A Review, Medicinal \& Aromatic Plants, 2014, 3(4): 1-6, doi: 10.4172/2167-0412.1000174
27. Gupta Rahul et al, Hypoglycaemic Activity of Ethanol Extract of Cinnamomum tamala Leaves in Normal and Streptozotocin Diabetic Rats, Iranian Journal of Pharmacology \& Theraputics, 2009, Vol. 8(1): 17-21.

\section{GRAPHICAL ABSTRACT}

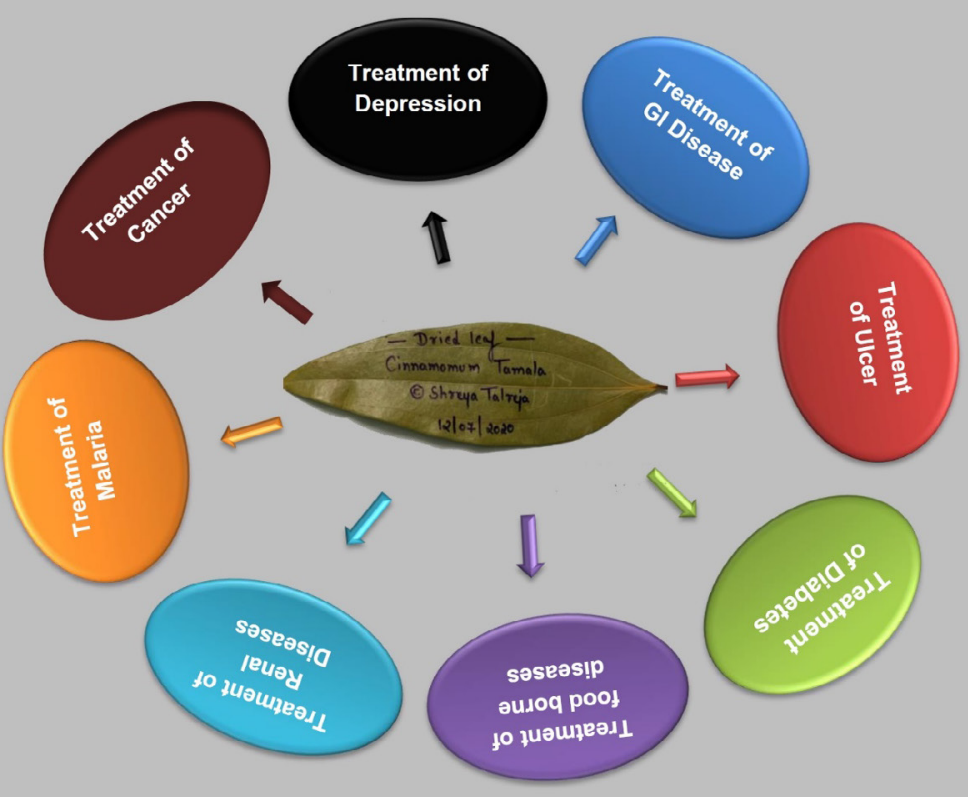

Graphical Abstract of the Importance of Cinnamoum Tamala in the Treatment of Various Diseases

\section{ABOUT AUTHORS}

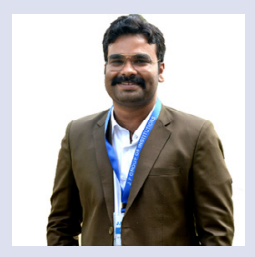

\section{Dr. Shashank Tiwari}

Prof. Dr. Shashank Tiwari is currently working as a Director Academic and Research in Lucknow Model College of Pharmacy, Lucknow, he is also a Certified Practitioner of Cognitive Behavioral Therapy (CBT), a Life and Spiritual Coach. Three patents in his name act as icing on the cake to support his professional acumen. $\mathrm{He}$ is an author of 5 national/international books. Dr. Tiwari is associated with various science promoting activities in India for the reform of Science and Technology. Award, Most Inspirational Director of the Year, Pride of National Pratibha Samman, Guru Vashishtha Samman, Best International Educator Award, Global Times Award for Teaching Excellence and many more. Various institutions have approached him to impart Guest Lectures on topics of Pharmacy and critical social issues.

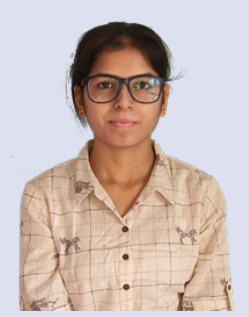

\section{Ms. Shreya Talreja}

Ms. Shreya Currently working as a Lecturer in the Department of Pharmaceutical Chemistry at Lucknow Model College of Pharmacy, Lucknow. Two Patents in his profile act as icing on the cake to support his profession acumen. She has published more than 20 review/research paper in national/International Journals. She is also an editorial board member of one of the leading International Journal and member of scientific bodies in India and abroad. Ms. Shreya has been awarded the best teacher Award by Institute of Technical and Scientific Research.

Cite this article: Tiwari S, Talreja S. Importance of Cinnamomum Tamala in the Treatment of Various Diseases. Pharmacogn J. 2020;12(6)Suppl:1792-6. 